\title{
EL MATRIMONIO HOMOSEXUAL A LA LUZ DE LOS SISTEMAS INTERAMERICANO Y EUROPEO DE DERECHOS HUMANOS, Y EL DESPLAZAMIENTO DE LA DOCTRINA DEL MARGEN DE APRECIACIÓN NACIONAL EN MÉXICO
}

\author{
HOMOSEXUAL MARRIAGE IN THE LIGHT OF THE INTER- \\ AMERICAN AND EUROPEAN HUMAN RIGHTS SYSTEMS, \\ AND THE DISPLACEMENT OF THE DOCTRINE FROM THE \\ NATIONAL MARGIN OF APPRECIATION IN MEXICO
}

Rogelio LÓPEZ SÁNCHEZ

Universidad Autónoma de Nuevo León, México

Recibido: 25 Mayo 2021 / Aceptado: 09 Julio 2021

\begin{abstract}
Resumen
El presente artículo examina los alcances y límites que ha tenido la figura del matrimonio homosexual en el marco de los sistemas interamericano y europeo de derechos humanos en relación con el margen de apreciación nacional de sus Estados miembros, y cómo la Suprema Corte de Justicia de la Nación mexicana (SCJN) ha adoptado una doctrina de reconocimiento pleno a esa institución civil como un Derecho Humano y desplazando dicho margen en detrimento del principio democrático. La Corte mexicana ha sido quizá el único tribunal en el mundo en obligar a todos los Estados de la Federación a reconocer por la vía jurisprudencial la institución del matrimonio de forma igualitaria (matrimonio igualitario) lo cual ha planteado una serie de consecuencias teóricasdificilmente superables, además de una distorsión del principio democrático en México.
\end{abstract}

Palabras clave: Matrimonio homosexual, Principio de igualdad, Margen de apreciación nacional, Discreción estatal, Cláusula de protección igualitaria, Principio democrático

\begin{abstract}
This paper analyzes constitutional scopes and limits about Same-Sex marriage in the frame of Interamerican and European Human Rights Systems regarding the margin of state discretion, and how Mexican Supreme Court has adopted full recognition of that civil institution as a human right shifting on democratic principle. Perhaps, this national Supreme Court has been almost theonly Court in the world thatrecognizes in its jurisprudence Same-Sex marriage base don equal protection clause. There fore, it has proposed several theoretical consequences hardly toovercome. Besides that situation, it hadal so modified thescope of the constitutional democratic principles inMéxico.
\end{abstract}


EL MATRIMONIO HOMOSEXUAL A LA LUZ DE LOS SISTEMAS INTERAMERICANO Y EUROPEO DE DERECHOS... Rogelio LÓPEZ SÁNCHEZ

2

Keywords: Same-sex marriage, Principle of equality, Margin of national appreciation, State discretion, Equal protection clause, Democratic principle 
SUMARIO: I. Introducción. II. Estado de la cuestión: el matrimonio como institución civil en México y medio para alcanzar el libre desarrollo de la persona. III. Limitaciones del matrimonio en los sistemas interamericano y europeo a partir de la doctrina del margen de apreciación nacional. IV. Posición de la SCJN sobre el matrimonio a partir del principio de igualdad y no discriminación. V. El reconocimiento jurisprudencial del matrimonio homosexual en México. Elementos de identidad constitucional y el desplazamiento del margen de apreciación nacional como deferencia para el legislador. VI. Bibliografía.

SUMMARY: I. Introduction. II. State of the question: marriage as a civil institution in México and a means to achieve the free development of the person. III. Limitations of marriage in the inter-American and European systems based on the doctrine of the national margin of appreciation. IV. Position of the SCJN on marriage based on the principle of equality and nondiscrimination. V. The jurisprudential recognition of homosexual marriage in México. Elements of constitutional identity and the displacement of the margin of national appreciation as a deference for the legislator. VI. Bibliography

\section{INTRODUCCIÓN}

El matrimonio fue concebido originalmente como una institución civil, pero hoy en día, Tribunales como el mexicano lo han elevado a la categoría de un Derecho Humano que forma parte del libre desarrollo de la personalidad y dignidad humana, desplazando así el margen de acción que tiene el legislador para crear normas y nuevos derechos. En la primera parte, se plantea el estado de la cuestión sobre esta figura como una institución que originalmente es civil, pero que ha sido reconocida su protección a través de garantías institucionales como el artículo 16 de la Declaración Universal de los Derechos Humanos o 17 de la Convención Americana sobre Derechos Humanos (CADH) (derecho a fundar una familia). Posteriormente se explican los límites a esta garantía institucional del matrimonio en los Sistemas Interamericano y Europeo de Derechos Humanos a la luz de la doctrina jurisprudencial más reciente de estos dos grandes órganos regionales. Pondremos énfasis en la doctrina del margen de apreciación nacional sobre esta figura en relación con el matrimonio homosexual en distintas naciones soberanas. Concluido dicho estudio, explicaremos el criterio jurisprudencial de la Suprema Corte mexicana que ha reconocido al matrimonio homosexual como parte del derecho al libre desarrollo de la personalidad y el principio de igualdad y no discriminación, en 
contraposición a la apreciación legislativa de algunas Entidades Federativas del Estado mexicano que se han negado a reconocerlo como tal.

\section{ESTADO DE LA CUESTIÓN: EL MATRIMONIO COMO INSTITUCIÓN CIVIL EN MÉXICO Y MEDIO PARA ALCANZAR EL LIBRE DESARROLLO DE LA PERSONA}

El matrimonio nace de una institución civil del derecho romano, posteriormente para pasará a ser parte del canónico, hasta llegar a su histórica secularización. En México, desde mediados del siglo XIX el presidente Benito Juárez promulga las Leyes de Reforma que postulaban como argumento toral la separación entre la Iglesia y el Estado. Así, con la Reforma dio nacimiento en México al matrimonio civil. Para el sistema jurídico mexicano lo anterior representa un hecho de capital importancia, pues con el pasar de los años quedarán de lado alegatos, como los usados en EE. UU., en el Caso Boers v. Hardwick, que sostenían que la ley representaba una tradición moral judeocristiana de carácter milenario como estándar moral social, y que, por ello, se justificaba la penalización a ciertas prácticas sexuales. ${ }^{1}$

A nivel internacional en Latinoamérica, conforme al artículo 11 de la CADH se protege a los individuos frente a las acciones arbitrarias de las instituciones estatales que afectan la vida privada y familiar. ${ }^{2}$ En razón de ello, en México se ha progresado en los ámbitos de discriminación a razón de diversidad sexual al abolir la pena a la homosexualidad o prácticas sodomitas desde 1871 . $^{3}$ Sin embargo, a pesar de que existen prejuicios y discriminación por parte de las personas entre sí, el Estado protege a todos los individuos, sin importar su orientación sexual, según el artículo $1^{\circ}$ constitucional. ${ }^{4}$ De ahí que para el sistema jurídico mexicano el matrimonio sea una institución social que se deriva del derecho humano a formar una familia, así como del principio de libre desarrollo de la persona, pero no es un derecho per se, es decir autónomo.

El hecho de que sea una institución considerada como componente esencial en la sociedad, cuya preservación se juzga indispensable para asegurar los principios constitucionales, estableciendo un núcleo o reducto indisponible por el legislador, no significa que sea, por un lado, la única manera de protección, y por otro la forma ideal para ello. ${ }^{5}$ Conforme con ello, el artículo 16 de la Declaración Universal de Derechos Humanos (DUDH), menciona que existe el derecho humano a fundar una familia, el cual no puede vedarse por cuestiones de raza, nacionalidad o religión; omite, sin embargo, cualquier otra limitación que deba evitarse y, por lo tanto, otorga a los Estados facultad para 
establecer los requisitos para el matrimonio, siempre y cuando no viole dicho precepto.

Ahora bien, al examinar las implicaciones de trato diferenciado que algunas normas pueden dar a sus destinatarios, la Corte Interamericana de Derechos Humanos (CoIDH) ha establecido que "no toda distinción de trato puede considerarse ofensiva, por sí misma, de la dignidad humana". ${ }^{6}$ En este mismo sentido, la Corte Europea de Derechos Humanos (CoEDH), basándose en "los principios que pueden deducirse de la práctica jurídica de un gran número de Estados democráticos", advirtió que sólo es discriminatoria una distinción cuando "carece de justificación objetiva y razonable". ${ }^{7}$ Es decir, que para la Corte es necesario justificar que el acceso al matrimonio, a fundar una familia y todos los derechos alrededor de la unión de dos personas heterosexuales, necesariamente conlleve a un menoscabo en la dignidad de las personas homosexuales, sin que ello suponga en ningún caso que la institución del matrimonio es un derecho humano per se.

Todos somos iguales ante la ley, y el grupo que busca el acceso al matrimonio tal como lo concebimos busca ser igual, pero como diría Norberto Bobbio “¿Igual a quién?”. ' Las uniones de hecho homosexuales, si bien son asimilables a las uniones por matrimonio, contienen en su núcleo algunas diferencias. Estas radican, por ejemplo, en el aseguramiento de una familia por las capacidades biológicas y los lazos filiales que por naturaleza de sangre se forman, con independencia de las posibilidades tecnológicas para lograr la perpetuación de la especie, de manera que ésta pueda más fácilmente persistir sin necesidad de aquella. Por ello, para la SCJN las parejas homosexuales y aquellas heterosexuales no son iguales en términos prácticos ni jurídicos, ni biológicos, en virtud del interés superior que es la familia y no el matrimonio en sí. ${ }^{9}$

Cualquier tipo de pareja, homosexual y heterosexual, merecen toda la protección de la ley y del Estado. Sin embargo, ello no supone la ampliación, modificación, aplicación especial o excepcional de las normas, pero sí da pie al estudio del caso y establecer el trato desigual a los desiguales en reconocimiento de su diversidad, ya que de ningún modo se busca vulnerar sus derechos u ofender su dignidad. Por ello es imposible afirmar que merecen (en términos prácticos) el exacto conjunto de derechos ambos tipos de parejas. No negamos (en ningún momento) que la dignidad intrínseca y el libre desarrollo de la persona humana deben ser los ejes rectores bajo los cuales se articulen las decisiones alrededor de los derechos de los homosexuales los cuales, invariablemente, son derechos humanos. Sin embargo, resulta extraño observar que la $\mathrm{CoIDH}$, en atención al numeral 17 de la $\mathrm{CADH}$, 
referente a la protección familiar, ha resuelto casos emblemáticos como el restablecimiento de los lazos familiares, ${ }^{10}$ o respecto a la posibilidad de procreación asistida entre otros que se encuentran plenamente concebidos también para los homosexuales, ${ }^{11}$ pero jamás se ha pronunciado sobre el matrimonio homosexual en el Sistema Interamericano de Derechos Humanos.

\section{LIMITACIONES DEL MATRIMONIO EN LOS SISTEMAS INTERAMERICANO Y EUROPEO A PARTIR DE LA DOCTRINA DEL MARGEN DE APRECIACIÓN NACIONAL}

No existe posición unívoca sobre los alcances del principio de no discriminación cuando se pondera contra las instituciones civiles como el matrimonio, así como los derechos y obligaciones que derivan del mismo. Existe un derecho a la familia según los artículos 17 de la CADH y 23 del Pacto Internacional de Derechos Civiles y Políticos (PIDCP). Sin embargo, la definición de matrimonio es contundente en cuanto a la modalidad, ya que los Estados parte del Tratado pueden solicitar condiciones y requisitos determinados al formar parte del denominado "dominio reservado". En temas coyunturales como éste, nos enfrentamos al interminable dilema sobre la tensión entre el principio democrático y de supremacía constitucional, pues en ocasiones el legislador al no contemplar la figura del matrimonio homosexual surge la interrogante sobre si el juez debe suplir esta omisión. ${ }^{12}$

El control de convencionalidad es un sistema donde jueces y magistrados están facultados para invalidar la norma por considerarla contraria a la CADH, o expulsarla del sistema jurídico; ${ }^{13}$ pero sin llegar al extremo de hacerlo legislando positivamente. ${ }^{14}$ Por ejemplo, en México, existen múltiples manifestaciones sobre las distintas concepciones de familia. A la fecha, en 19 Entidades federativas se pueden celebrar matrimonios homosexuales. Dos de esos Estados lo reconocen como un derecho humano en su Constitución y Código Civil (Ciudad de México y Morelos), en tanto que 9 Estados más lo reconocen únicamente en su Código Civil como una institución (Baja California Sur, Coahuila, Nayarit, Hidalgo, Colima, Michoacán, San Luis Potosí, Campeche y Oaxaca) en tanto que el resto de los Estados federales no han reformado para incluir esta figura en sus legislaciones.

No obstante, la duda radica en si existe la necesidad de modificar, ampliar o agregar una figura especial en virtud de la razonabilidad objetiva, además de definir claramente si a partir de las uniones entre personas homosexuales, nacen los mismos derechos y deberes que de aquellas surgidas entre parejas heterosexuales (matrimonio o concubinato). El artículo 32.1 de la $\mathrm{CADH}$ 
afirma el deber de las personas para con la familia, la comunidad y la humanidad. En este carácter, existen limitaciones a los derechos por los de terceros, la seguridad de las personas y por las justas exigencias del bien común, en una sociedad democrática. Este último concepto se relaciona con el principio democrático alrededor del matrimonio, que es también de orden y trascendencia social y no sólo privada. ${ }^{15}$

En el ámbito internacional, no existen tratados específicos para este grupo de población que son las parejas homosexuales, ya que no se hace mención particular sobre las cuestiones alrededor de la orientación sexual o de la identidad de género de manera explícita. Los principios de Yogyakarta es el instrumento internacional más específico respecto a los derechos de las personas con orientación sexual diversa a la heterosexual. ${ }^{16}$ Sin embargo, México no es parte de dicho instrumento, $y$, además, a pesar de profundizar en cuanto a los derechos civiles y políticos como los derechos económicos, sociales y culturales, hasta el momento no ha causado reacciones oficiales por parte del Sistema de Naciones Unidas ni del Gobierno Mexicano. Los mínimos incluidos en dicho instrumento no obligan a ningún Estado a configurar dentro de sus leyes una paridad en el acceso a instituciones jurídicas o modificar los requisitos de éstos en favor a ellos. En México el artículo 30 constitucional señala: "La mujer o el varón extranjeros que contraigan matrimonio con varón o con mujer mexicanos, que tengan o establezcan su domicilio dentro del territorio nacional y cumplan con los demás requisitos que al efecto señale la ley", contemplando únicamente como partes al celebrar el acto jurídico del matrimonio son una mujer con un varón o un varón con una mujer, sin prever ninguna otra fórmula para el pacto matrimonial.

A pesar de que ya exista en algunos lugares la extensión del alcance matrimonial o de concubinato, estos son reflejos de sus Estados y la realidad de cada Estado es muy diferente. Para que estos derechos y la figura pueda ser reconocida plenamente, debe de existir una demanda tanto de parejas homosexuales y heterosexuales, como parte de una sociedad incluyente. En la decisión No. 2010-92 derivado de una queja en contra del Consejo Constitucional Francés, alzando el cuestionamiento sobre la invocación de una protección constitucional por personas que no responden a las condiciones de fondo del matrimonio, este Consejo se negó. ${ }^{17}$

Por su parte, el TEDH admitiendo que la interpretación al artículo en cuestión de este caso no excluiría el matrimonio homosexual, advierte que es un derecho para llevar una cierta manera de vida, no un derecho a un determinado estatus jurídico, ${ }^{18}$ el cual no atenta contra su vida familiar normal, ya que no necesariamente un estado jurídico en específico (verbigracia, el 
matrimonio) es el único que se puede brindar a una persona para el pleno reconocimiento de su dignidad y su libre desarrollo. Finalmente, el TEDH ha dejado en claro que los Estados parte no se encuentran obligados a legislar o reconocer el matrimonio homosexual como derecho fundamental, pues es parte del ámbito de la soberanía de cada Estado en su margen de apreciación de cada estatus conferido y al reconocimiento de éste. ${ }^{19}$

Recientemente dicho órgano regional ha sostenido que, ante la ausencia de un consenso europeo, el reconocimiento de un matrimonio homosexual implica cuestiones de carácter moral y ético, por lo que, acorde al artículo 12 del CEDH (Convenio Europeo de Derechos Humanos): “(...) es cierto que algunos de los Estados Contratantes han extendido el matrimonio a parejas del mismo sexo, el Artículo 12 no puede interpretarse como una imposición a los Estados Parte de una obligación de garantizar a parejas del mismo sexo el acceso al matrimonio". ${ }^{20}$ En el Sistema Interamericano, por otra parte, el artículo 17.2 de la CADH reconoce el matrimonio heterosexual, por tanto, las leyes internas protegen a las personas de toda discriminación, aunque también es verdad que impone condiciones para acceder al matrimonio únicamente.

\section{POSICIÓN DE LA SCJN SOBRE EL MATRIMONIO A PARTIR DEL PRINCIPIO DE IGUALDAD Y NO DISCRIMINACIÓN}

Ferrajoli afirma que todos los derechos fundamentales han sido establecidos como resultado de luchas o revoluciones que han roto el velo de normalidad y naturalidad que ocultaba una precedente opresión o discriminación. ${ }^{21} \mathrm{La}$ igualdad debe ser parámetro fundamental en la organización y estructuración en todos los ámbitos de la vida social democrática. Se deben eliminar tanto las barreras formales como las de carácter informal..$^{22}$ La prohibición de discriminación es un complemento técnico del principio de igualdad, $\mathrm{y}$ materialmente, implica en el derecho un equilibrio en las condiciones materiales básicas de la vida: bienes, situación económica y situación social. ${ }^{23}$ No obstante, en México no se llega a la plenitud y el otorgamiento de un conjunto incompleto de derechos sólo refleja una doble discriminación, pues por un lado se priva a las parejas homosexuales de los beneficios expresivos del matrimonio y por el otro de los beneficios materiales. ${ }^{24}$

La Suprema Corte mexicana (SCJN) ha sostenido que la familia no debe ser considerada como una persona jurídica con independencia de sus constituyentes, sino como organismo jurídico, en vista de que sus miembros no poseen derechos individuales como integrantes de ella, sino que subsiste una vinculación recíproca de interdependencia entre ellos. Es decir, una 
subordinación a un fin superior, conceptualizada como la solidificación de las posibilidades de relación entre los miembros por medio de una decisión inviolable para crear condiciones sociales, culturales, económicas y políticas para que esas posibilidades sean realizables. ${ }^{25}$ El matrimonio, por lo general, trae aparejada como finalidad la "perpetuación de la especie", es decir, la procreación. No obstante, considerar esta finalidad como necesaria, ${ }^{26}$ no se adecua a los fundamentos actuales del matrimonio ni de la familia, ${ }^{27}$ y excluye injustificadamente a las parejas homosexuales del acceso a esta institución, ${ }^{28}$ así como de la protección a su unión y sus familias, de la manera de formar una familia a través de figuras como la adopción, reproducción asistida, entre otras. $^{29}$

Por su parte, la CoIDH ha señalado que los tratados de derechos humanos son instrumentos vivos "cuya interpretación tiene que acompañar la evolución de los tiempos y las condiciones de vidas actuales". ${ }^{30}$ Las categorías sospechosas con base en un trato diferenciado constituyen focos rojos al presumirse como ilegítimas. ${ }^{31}$ En el caso Karen Atala -en el que se niega la tutela de las hijas a una mujer por ser lesbiana-, la CoIDH determinó que "los criterios específicos en virtud de los cuales está prohibido discriminar (...) no son un listado taxativo o limitativo sino meramente enunciativo" y, en consecuencia, bajo la categoría "cualquier otra condición social" se encuadra la prohibición de no discriminar por orientación sexual". ${ }^{32}$

Una de las manifestaciones de protección a la familia puede darse mediante la institución del matrimonio o concubinato. Ahora bien, si se observa detenidamente, en México el propósito del matrimonio es multifacético debido a su federalismo (cada Entidad Federativa tiene facultades para definirlo). No obstante, encontramos algunas constantes, tales como vivir en el mismo domicilio, guardarse fidelidad, decidir de manera libre, responsable e informada el número y espaciamiento de sus hijos, entre otras; en cuanto a la reciprocidad, dejan en claro que los derechos y obligaciones que arriban con el matrimonio deberán ser siempre iguales para los cónyuges e independientes de la aportación económica al sostenimiento del hogar que éstos tengan, entre muchas más.

Al acceder al matrimonio nacen un cúmulo de derechos que la SCJN clasifica en beneficios fiscales, de solidaridad, por causa de muerte de uno de los cónyuges, de propiedad, en la toma subrogada de decisiones médicas y migratorios, ${ }^{33}$ que sólo se ven restringidos e inaccesibles al tratar a los homosexuales de modo diferente sin justificación racional para ello. ${ }^{34}$ En este contexto, la SCJN afirmó que era insostenible aseverar que el matrimonio 
en su definición tradicional es un concepto completo, dogmatizado por el legislador, pues nos enfrentamos a la histórica secularización de la sociedad y de la institución misma.

Parte de las características o añadiduras de contraer matrimonio es el hecho de: (i) decidir, y (ii) vivir bajo los términos y condiciones de este contrato. Esto se vincula con el desarrollo natural y libre desarrollo de la persona humana. ${ }^{35}$ En este caso concreto, al unirse a otra persona y crear una unión, se manifiesta la elección de formar una vida en común y la posibilidad de tener hijos como parte de su humanidad, sus relaciones afectivas, ${ }^{36}$ las cuales se ligan invariablemente a su orientación sexual. Al estar prohibida toda forma de discriminación en comunión con el artículo uno de la Carta Magna, el hecho que la pareja sea de un mismo sexo no debe influir en el conjunto de derechos y obligaciones que se le entrega a esta unión, mucho menos negar su reconocimiento. De este modo, su pertenencia a un grupo social en situación vulnerable provoca que se enfrenten a situaciones de riesgo o discriminación que les impiden alcanzar mejores niveles de vida, y por ello, requieren de la atención e inversión del Gobierno para lograr su bienestar. ${ }^{37}$

El matrimonio es una institución cuyo fin primordial consiste en la conformación de una familia. En cambio, el concubinato se instituyó por la falta de affectio maritalis, es decir, la falta de exclusividad y permanencia de la pareja. ${ }^{38}$ Las regulaciones legales en parejas que no se encuentran casadas y viven juntas son bastante complejas. ${ }^{39}$ En México, la permanencia se impone para la conformación de un concubinato, variando de entre 2 a 5 años, o bien, la existencia de un hijo en común, y si se tiene varias concubinas, ninguna se considera como tal, por lo que el affectiomaritalis prevalece; sin embargo, esta relación conlleva derechos y obligaciones recíprocos entre concubinos. Con lo anterior se confirma el espíritu de discriminación en base a estereotipos o prejuicios sociales, estigmas que se han acarreado a lo largo de la historia en contra de los homosexuales, que cumpliendo con todos los requisitos, no se les otorga el acceso a las figuras institucionalizadas, es decir, que sea una "mera relación de hecho". ${ }^{40}$

Por tanto, se aplica un trato diferente, pero esto no ocurre con la misma relación de hecho heterosexual, a pesar de compartir con esta figura la convivencia, solidaridad, ayuda mutua, permanencia, publicidad, igualdad, fidelidad, cohabitación y respeto mutuo, valores fundamentales en las relaciones humanas, dictadas por la necesidad natural de un sentido de pertenencia y amor. ${ }^{41}$ De ahí que se pugne por la igualdad en ambas situaciones. La autonomía de la persona se traduce en la eliminación de 
cualquier tipo de barrera, a fin de brindar una adecuada equiparación de oportunidades, toda vez que una pareja homosexual hace imposible la procreación biológica de ambos. ${ }^{42}$ La naturaleza humana en su intrínseca complejidad, se manifiesta en uno de sus aspectos por la preferencia sexual, la cual la orientará en su proyección de vida. En las parejas heterosexuales y fértiles, subsiste la posibilidad de cumplir con uno de los fines del matrimonio: la procreación; o bien, mediante el concubinato. La consideración biológica como eje en las relaciones resulta exclusiva, cerrada e incompatible con la sociedad moderna. ${ }^{43}$

Además, gracias a la tecnología (fecundación in vitro, entre otras) y la adopción, la reproducción sexual no es condición sine qua non para formar una familia, y cumplir uno de los fines del matrimonio. Es decir, con el simple hecho de que sean dos personas basta. Además, existen familias en las que la reproducción no es el objetivo principal y aun así existen figuras para protegerlos tales como el concubinato o la sociedad de convivencia, ${ }^{44}$ al mismo tiempo que el matrimonio no exige la plena fertilidad para contraerlo. Por estos motivos, ha dicho la SCJN es irracional la exigencia de perpetuación de la especie, así como el condicionamiento que sea entre un sólo hombre y una sola mujer, ${ }^{45}$ ya que además, se trataría de delimitar la protección a la familia, donde la formación de ésta es inherente al ser humano, ${ }^{46}$ de tal manera que es imposible que se restrinja el ejercicio de este derecho. Por ello, el Estado es responsable de proteger tal institución a partir del artículo $4^{\circ}$ párrafo primero de la Constitución Federal, además de constituir una oposición a la autonomía de la voluntad relacionada con el libre desarrollo de la persona. ${ }^{47}$

El principio de igualdad se traduce en el reconocimiento de que todos los seres humanos somos diversos y que se debe frenar a las diversidades de que pesen como factores de desigualdad. Según la Constitución mexicana, todas las familias sin importar su origen son dignas y merecedoras de protección sin importar las preferencias sexuales en ello. ${ }^{48}$ Concibiendo el acceso al matrimonio como derecho humano, la libertad configurativa del legislador se encuentra limitada y la restricción, exclusión o preferencia en el ejercicio de este derecho es una clara violación a los derechos de la persona. ${ }^{49}$

Como conclusión, la SCJN sostiene que el matrimonio entre parejas del mismo sexo es una nueva forma familiar que parece estar destinada a la aceptación social. Las alternativas al matrimonio tradicional (tal como el concubinato en su momento) producirán cambios en el derecho familiar y continuarán reflejando las nuevas prácticas sociales en cuestión de género como aceptable en la población. ${ }^{50} \mathrm{El}$ actual estado de vulnerabilidad desafía 
los estándares sociales y reta al Estado a tomar las medidas necesarias para combatir ese problema. ${ }^{51}$ No obstante, se genera un pánico público y se azuza a la "mayoría moral" para despertar las ansiedades sociales y romper paradigmas. Esta ceguera provoca ignorar que regulando adecuadamente se vive un proceso de mejora para todos, no sólo para aquellos con orientación sexual diferente a la heterosexual, pues no se trata de "privilegios", sino de derechos y obligaciones (en el caso del matrimonio o concubinato). ${ }^{52}$

El Alto Comisionado de las Naciones Unidas para los Derechos Humanos en México ha cuestionado la percepción tanto del gobierno como de la sociedad, que ridiculiza o mira como anormal las preferencias sexuales diferentes a la heterosexualidad, porque la multiplicidad de derechos que se ven vulnerados gracias a pobres tomas de decisiones, escuetas políticas públicas, ambiguas legislaciones $\mathrm{o}$, incluso, deliberada omisión de regulación, son por demás graves. ${ }^{53}$ Ante esta situación, la SCJN ha desarrollado una doctrina de reconocimiento jurisprudencial que ha dejado absolutamente despejado la materialización del matrimonio en parejas homosexuales. ${ }^{54}$ Acorde a esto, el derecho a formar una familia debe ser en condiciones de igualdad. ${ }^{55}$ Por tanto, urge el estudio y establecimiento de una regulación igualitaria y total, completa, equitativa, consciente de la necesidad de los ciudadanos que viven marginados de los beneficios que se derivan de las instituciones creadas exclusivamente para heterosexuales, y que irracionalmente siguen fomentando la intolerancia.

Por ello, el Estado (conforme a lo dispuesto en el artículo $5^{\circ}$ de Convención sobre la eliminación de todas las formas de discriminación contrala mujer) debe adoptar todas las medidas adecuadas para lograr eliminar los prejuicios y las prácticas que se basen en la idea de inferioridad o superioridad de los sexos o roles estereotipados para hombres y mujeres. Conforme a la intención constitucional "extender las garantías implícitas en el principio de igualdad al ámbito de las acciones legislativas que tienen un impacto significativo en la libertad y la dignidad de las personas" ${ }^{\$ 6}$ así como lo establecido en el artículo 17 de la CADH y el artículo 23 del PIDCP, no cabe duda de la magnitud y amplitud que debe considerarse ante el caso que nos congrega, por ello sólo resta la legislación pertinente para volverlo una realidad y acabar con la opresión de la tiranía de una mayoría.

V. EL RECONOCIMIENTO JURISPRUDENCIAL DEL MATRIMONIO HOMOSEXUAL EN MÉXICO. ELEMENTOS DE IDENTIDAD CONSTITUCIONAL Y EL DESPLAZAMIENTO DEL 


\section{MARGEN DE APRECIACIÓN NACIONAL COMO DEFERENCIA PARA EL LEGISLADOR}

El reconocimiento jurisprudencial que hace la SCJN sobre el matrimonio homosexual impone una visión de completa igualdad (nótese el uso del término diverso a "equidad"), obliga a recalcar la imperiosa necesidad de continuar con un proceso dialéctico y plural en torno al debate de esta figura, pero sobre todo a comprender que éste no es infalible. ${ }^{57}$ Es decir, es un proceso orientado hacia un fin que debe cumplir con ciertos requisitos de forma y fondo para que las bases de la sociedad en el espíritu del estado de Derecho, se concreten con las fuerzas y herramientas suficientes y adecuadas para su mejor permanencia y aplicación. Ante una omisión legislativa, debe seguirse el procedimiento adecuado para subsanarlo y respetar aquello dispuesto en nuestra Constitución respecto a la separación de poderes. De este modo, sólo el legislador puede decir qué derechos se reconocen; ${ }^{58}$ en suma, se debe respetar la competencia del legislador. ${ }^{59}$

La decisión, si bien se fundamenta en resoluciones de diversos Tribunales Supremos de los Estados Unidos de Norteamérica, la realidad que se vivió allá es diversa a la sucedida en México. En aquel país, la liberalización inicia con los movimientos sociales y políticos entre voces de minorías raciales, olas feministas y manifestaciones estudiantiles, así como los movimientos antiguerra y el impacto por la lucha de los derechos de los homosexuales. ${ }^{60}$ A partir de ello, la vida gay en aquel país se convirtió en algo más visible y comenzó la movilización de un engranaje a favor de la igualdad. A pesar de la decisión de la American Psychiatric Association Broad of Trustees en 1973 que acordó que la homosexualidad no es una enfermedad mental, y del triunfo del caso Lawrence vs. Texas, en el 2003, el camino hacia la igualdad dista mucho de llegar a su fin. ${ }^{61}$

La actitud asumida por la SCJN sobre el matrimonio homosexual implica una serie de problemas teóricos, que además imposibilitan el encaje de su doctrina en la realidad social del país. El concepto evolutivo de dignidad de la persona implica, según Fukuyama, que $s u$ reconocimiento se debe no sólo a una clase limitada de personas, sino a todos; de forma que la ampliación y universalización de la dignidad convierte esa aspiración de reconocimiento en un proyecto político. ${ }^{62}$ Ciertamente, la implementación de políticas públicas a favor de las minorías no significa por sí mismas tener que transformar o desaparecer toda una institución, sino cambiar y fomentar políticas que eliminen la discriminación para que la opinión pública cambie y avale el cambio y entonces el tema será ese. 
En este sentido, la doctrina jurisprudencial de la SCJN no procura exclusivamente la implementación de una política pública, sino más bien la adopción de una decisión de moral pública sin el respaldo social o la legitimación de la representación popular. El reconocimiento jurisprudencial del matrimonio homosexual tiene la peculiaridad, además, de someter a los Estados miembros de la República mexicana a su particular interpretación de la Constitución federal, pareciendo evocar la noción jurídica de identidad constitucional como salvaguarda del principio de igualdad previsto en la constitución y sustraído por completo al desarrollo que haga del mismo el legislador local, anulando por completo el ejercicio de su libre autodeterminación en materia de matrimonio. ${ }^{63}$

Si rastreamos los orígenes la noción de identidad constitucional en la jurisprudencia europea, tenemos que la misma se forja como correlato a la teoría de los controlimiti en el marco de la tutela multinivel, ${ }^{64}$ en virtud de lo cual la interpretación del principio de igualdad subyacente al régimen legal del matrimonio hecha por la SCJN, serviría para alegar que su posición garantista se incardina en esa noción de identidad constitucional de México. Tampoco esa parece una justificación plausible. Como se mencionó en el primer epígrafe de este trabajo, el Sistema Interamericano jamás se ha pronunciado sobre las obligaciones de los Estados miembros en relación al matrimonio homosexual. Por lo tanto, la ausencia de un diálogo multinivel inteamericano sobre la cuestión del matrimonio homosexual, torna imposible argumentar que la SCJN ha optado por una interpretación más favorable del principio de igualdad al amparo de una identidad constitucional forjada a través de su doctrina.

Por otro lado, tenemos que, según un importante jurista alemán, "la identidad social está basada en la Constitución, cuando la Constitución como tal o, al menos, algunos de los institutos jurídico-constitucionales juegan un papel importante en la formación o en los cambios de esos momentos". ${ }^{65}$ Resulta, sin embargo, que la posición garantista asumida por la SCJN tampoco responde a una pretensión social de identidad con la causa homosexual; tal vez ello explique las razones por las cuales la propia $\mathrm{SCJN}$, al alegar una aparente omisión legislativa, termina por sustituirse en el legislador, sin justificar la necesidad de adaptar su lectura constitucional a una realidad social que no lo demanda.

La decisión de reconocer el matrimonio y concubinato homosexual por la SCJN vulnera el principio democrático, la cual señala que únicamente el legislador está autorizado para tomar las decisiones que le competen a la mayoría. Esta especie de "garantismo espurio" no es suficiente para transformar una realidad social; se requiere de instituciones eficaces para la 
aplicación de la legislación no discriminatoria, políticas públicas dirigidas exclusivamente a este grupo de población, que busquen un cambio cultural, sobre todo, datos que permitan graduar el progreso que se alcance para proceder a la legislación exacta, precisa y completa. Dejar al juez la decisión de lo que tenemos que decidir democráticamente arroja una importante y peligrosa labor a los jueces, que, en aras de alcanzar la legitimación social, pudieran tensar peligrosamente el principio democrático, en aras de buscar ese "garantismo" de derechos máximos, a costa de fagocitar la democracia deliberativa.

\section{BIBLIOGRAFÍA}

Agencia Estatal Boletín Especial del Estado, Tribunal Constitucional (2012), en Boletín Oficial del Estado, ${ }^{\circ} 286$, publicado miércoles 28 de noviembre.

BANCHS RODRÍGUEZ, M. A. "Identidades de Genero en la Encrucijada De La Sociedad Matrilineal Al Umbral De La Posmodernidad", http://webs.u vigo.es/pmayobre.

BÉRUBÉ, A. (2011), "My Desire of History”, en Essays in Gay, Community and Labor History, The University of North Carolina Press, Chapel Hill. $\mathrm{h}$ ttps://doi.org/10.5149/9780807877982_berube

BOBBIO, N., Igualdad y libertad, Barcelona, Paidós

BON BOGDANDY, A. (2005), "Identidad constitucional -exploración de un fenómeno ambiguo con ocasión de la política de identidad europea de lege lata y lege ferenda-", Revista Española de Derechos Constitucional, $\mathrm{n}^{\circ} 75$.

BON, P. (2014), "La identidad nacional o constitucional, una nueva noción jurídica”, Revista Española de Derecho Constitucional, nº 100.

CERDÁ MARTÍNEZ-PUJALTE, C. (2005), "Los principios constitucionales de igualdad de trato y de prohibición de la discriminación: un intento de delimitación", Cuadernos Constitucionales de la Cátedra Fadrique Furió Ceriol, ${ }^{\circ}$ 50-51.

Consejo Nacional para Prevenir la Discriminación, Secretaría de Gobernación (2010), Encuesta Nacional sobre Discriminación en México, México D.F.

DE VEGA GARCÍA, P. (1983), "Constitución y democracia", en LÓPEZ PINA, A. (Ed.), La Constitución de la Monarquía parlamentaria, Fondo de Cultura Económica, México.

DEVI, S. (1977), The World of Homosexuals, Bell Books editions, New Delhi. FERRAJOLI, L. (2006), "Sobre los Derechos Fundamentales", Revista Mexicana de Derecho Constitucional (Cuestiones Constitucionales), $\mathrm{n}^{\circ} 15$. 
FRAGER, R. y FADIMAN, J. (2000), Abraham Maslow y la psicología transpersonal, Oxford University Press, $2^{\mathrm{a}}$ Edición.

FUKUYAMA, F. (2019), Identidad. La demanda de dignidad y las políticas de resentimiento, Ariel.

GARCÍA MORELOS, G. (2010), El control judicial difuso de convencionalidad de los Derechos Humanos por los tribunales ordinarios en México, Ubijus, México.

HABERMAS, J. (1998), Facticidad y validez, Madrid, traducción M. Jiménez Redondo.

HABERMAS, J. (1998), Escritos sobre Moralidad y Eticidad, Paidós Ibérica, Barcelona.

HUNTER, N. D. (2012), The future impact of same sex marriage: More questions than answers, Georgetown University Law Center, Washington, D.C., $\mathrm{n}^{\circ} 12-146$.

Informe de la reunión de especialistas "Género, pobreza, raza, etnia: estado de la situación en América Latina", Santiago de Chile, 2006. http://www.cndh.org.mx/sites/all/fuentes/documentos/Eventos/Conv ocatorias/bibliografia/InformeReunionEspecialistas.pdf

LAX, J. R. y PHILLIPS, J. H. (2008), "Gay Rights in the States: Public and Policy Responsiveness", American Political Science Review, v. 103 n 3, agosto. https://doi.org/10.1017/S0003055409990050

MONROY GUEVARA, P. J. Reflexiones en torno a la tutela constitucional de la dignidad humana en el Estado Mexicano (Breve referencia con el Gobierno Español), Publicaciones de los Becarios de la Corte, No. 39, Suprema Corte de Justicia de la Nación, México D.F.

NEWTON, D. E. (2009), Gay and Lesbian Rights: A Reference Handbook, ABC-CLIO, Second Edition.

Oficina del Alto Comisionado de las Naciones Unidas para los Derechos Humanos en México (2003). Diagnóstico sobre la situación de los Derechos Humanos en México, Mundi-Prensa, México, D.F.

Oficina Internacional del Trabajo, "Discriminación en el lugar de trabajo", en Resumen Analítico. Declaración relativa a los Principios y Derechos Fundamentales en el Trabajo. Disponible en: http://www.ilo.org/wcmsp5/groups/public/---ed_norm/---declaration/d ocuments/publication/wcms_decl_fs_114_es.pdf

PALACIOS, A. y ROMAÑACH, J. (2008), "El Modelo de la Diversidad: Una Nueva Visión de la Bioética desde la Perspectiva de las Personas con 
Diversidad Funcional (Discapacidad)", Intersticios, Revista Sociológica de Pensamiento Crítico, 2(2).

PALACIOS, R. (2011), La Conspiración del Movimiento Gay, Mandala Ediciones, Madrid.

PÉREZ CONTRERAS, M. de M. (2000), Derechos de los Homosexuales, Nuestros Derechos, Cámara de Diputados, LVIII Legislatura, Universidad Nacional Autónoma de México, México, D.F.

REY CANTOR, E. (2008), Control de convencionalidad de las leyes y Derechos Humanos, Porrúa, México.

ROMAÑACH CABRERO, J. (2009), Bioética al otro lado del espejo (La visión de las personas con diversidad funcional y el respeto a los derechos humanos), Venezuela.

ROMBOLI, S. (2017), "Los contra-limites en serio y el caso Taricco: el largo recorrido de la teoría hasta la respuesta contundente pero abierta al diálogo de la Corte Constitucional Italiana", Revista de Derecho Constitucional Europeo, $\mathrm{n}^{\mathrm{o}} 28$.

SALAZAR UGARTE, P., AGUILÓ REGLA, J., et. al. (2009), Garantismo espurio, Fundación Coloquio Jurídico Europeo, Madrid.

V.V.A.A. Amnistía Internacional (2001), Crímenes de Odio, Conspiración de Silencio Tortura Y Malos Tratos Basados En La Identidad Sexual, Editorial Amnistía Internacional (EDAI), Madrid.

V.V.A.A. Amnistía Internacional (2006), El derecho a la orientación sexual, en Colección AI-Educa, http://www.cndh.org.mx/sites/all/fuentes/documen tos/Eventos/Convocatorias/bibliografia/DerechoOrientacionSexual.pdf

V.V.A.A. Amnistía Internacional (2004), Los derechos humanos y la orientación sexual e identidad de género, Editorial Amnistía Internacional (EDAI), Londres.

VA: American Psychiatric Association (1973), Homosexuality and sexual orientation disturbance proposed change in DSM-II, Sexta impresión. Retiro de declaración de posición, Arlington.

VASCONCELOS MÉNDEZ, R. (2010), Una Corte para la Constitución (Justicia Constitucional y democracia en México), UNAM-IIJ.

ZÚÑIGA ORTEGA, A. V. (2011), Concubinato y familia en México, Biblioteca Digital de Humanidades, Universidad Veracruzana, Veracruz. 


\section{FUENTES}

\section{Fuentes legislativas nacionales}

Constitución Política de los Estados Unidos Mexicanos.

Ley General de Desarrollo Social, Diario Oficial de la Federación, México, 20 de enero de 2004.

\section{Fuentes legislativas internacionales}

Principios de Yogyakarta, Principios sobre la Aplicación de la Legislación Internacional de Derechos Humanos en Relación con la Orientación Sexual y la Identidad de Género.

Propuesta de Modificación a la Constitución Política de Costa Rica relacionada con la Naturalización, supra nota 34.

\section{Fuentes jurisprudenciales nacionales}

Acción de Inconstitucionalidad 2/2010, resuelta el 16 de agosto de 2010

Amparo Directo en Revisión 259/2013, resuelto el 30 de octubre del 2013. Amparo en Revisión 581/2012, resuelto el 5 de diciembre de 2012

Controversia Constitucional 14/2010, resuelta el 23 de enero de 2012.

Tesis 1a. CIII/2013, Semanario Judicial de la Federación y su Gaceta, Décima Época, $1^{\text {a }}$ Sala, S.J.F. y su Gaceta, p. 962.

Tesis: 1a. XCIX/2013, Semanario Judicial de la Federación y su Gaceta, Décima Época, t. I, abril de 2013, p. 961

Tesis: CXXXIII/2004, Primera Sala Novena Época, Semanario Judicial de la Federación y su Gaceta XX, diciembre de 2004, p. 361.

Tesis: P. LXVI/2009, Semanario de la Suprema Corte de Justicia y su Gaceta, Novena Época, t. XXX, diciembre de 2009.

Tesis P. LXVII, Semanario Judicial de la Federación y su Gaceta, Décima Época, t. I, diciembre de 2011, p. 535.

Tesis: 1a. CCLVIII/2014 (TA), $10^{\text {a }}$ Época, $1^{\text {a }}$ Sala, Semanario Judicial de la Federación, publicación: viernes 04 de julio de 2014 08:05 h 
Tesis: 1a. CCLX/2014 (TA), Décima Época, $1^{\text {a }}$ Sala, Semanario Judicial de la Federación, publicación: viernes 04 de julio de 2014 08:05 h

Tesis: 1a. CCXV/2014, Gaceta del Seminario Judicial de la Federación, Décima Época, t. I, mayo de 2014, p. 548;

Tesis: 1a. CIII/2013 (TA); Décima Época, 1ª Sala, S.J.F. y su Gaceta, p. 962.

Tesis: 1a. CV/2013, Seminario Judicial de la Federación y si Gaceta, Décima Época, t. I, abril de 2013, p. 963.

Tesis: 1a. CV/2013, Seminario Judicial de la Federación y su Gaceta, Décima Época, t. I, abril de 2013, p. 963.

Tesis: 1a. CV/2013, Seminario Judicial...op.cit. p. 963

Tesis: P. LXVII/2011(9a.), Semanario Judicial de la Federación y su Gaceta, Décima Época, p.535

\section{Fuentes Jurisprudenciales Internacionales}

Consejo Constitucional, Sentencian ${ }^{\circ} 2010-92$, Question Prioritaire de Constitut

Constitutionalité, Francia, de 28 de enero de 2011. https://doi.org/10.1016/ S1773-035X(10)70518-9

Corte Europea de Derechos Humanos, Schalk and Kopf c. Austria, 24 de junio 2010.

Corte IDH, Caso Atala Riffo y niñas vs. Chile, Sentencia de 24 de febrero de 2013.

Corte IDH. Caso Artavia Murillo y otros (Fertilización in vitro) Vs. Costa Rica. Excepciones Preliminares, Fondo, Reparaciones y Costas Sentencia de 28 noviembre de 2012 Serie C No.257.

Corte IDH. Caso Artavia Murillo y otros (Fertilización in vitro) Vs. Costa Rica. ExcepcionesPreliminares, Fondo, Reparaciones y Costas Sentencia de 28 noviembre de 2012 Serie C No.257.

Corte IDH. Caso Masacre de las Dos Erres Vs. Guatemala. Excepción Preliminar, Fondo, Reparaciones y Costas. Sentencia de 24 de noviembre de 2009. Serie C No. 211. 
Eur. Court H.R., Case "relating to certain aspects of the laws on the use of languages in education in Belgium" v. Belgium, Juicio de 23 de Julio, 1968, Series A 1968.

Eur. Court H.R., Case of Petrovic v. Austria, Juicio de 27 de Marzo, 1998, Reportes 1998-II. Eur. Court H.R., Case of Wessels-Bergervoet v. TheNetherlands, Juicio de 4 de Junio, 2002. Eur. Court H.R., Case of Willis v. The United Kingdom, Juicio de 11 de Junio, 2002.

* $\quad$ Profesor Investigador. Universidad Autónoma de Nuevo León, México. Orcid: https://orcid.or g/0000-0002-2725-2887. Contacto: rlopezs@uanl.edu.mx

1 Blackmun, J., dissenting, Bowers vs. Hardwick 478 U.S. 186, 30 de junio de 1986.

2 Corte IDH. Caso Artavia Murillo y otros (Fertilización in vitro) vs. Costa Rica. Excepciones Preliminares, Fondo, Reparaciones y Costas Sentencia de 28 noviembre de 2012 Serie C No. 257, Párrafo 142.

3 NEWTON, D. E. (2009), Gay and Lesbian Rights: A Reference Handbook, ABC-CLIO, Second Edition, p. 86.

4 Consejo Nacional para Prevenir la Discriminación, Secretaría de Gobernación (2010), Encuesta Nacional sobre Discriminación en México, México D.F.

5 Resultando Tercero. Controversia Constitucional 14/2010, resuelta el 23 de enero de 2012.

6 Opinión Consultiva OC-4/84, del 19 de enero de 1984. Propuesta de Modificación a la Constitución Política de Costa Rica relacionada con la Naturalización, supra nota 34, párr. 55.

7 CoEDH Casos: Willis v. The United Kingdom, Jugdment of 11June, 2002, parr. 39; WesselsBergervoet v. The Netherlands, Jugdment of 4th June, 2002, párr. 42; Petrovic v. Austria, Judgment of 27th of March, 1998, Reports 1998-II, párr. 30; Case "relating to certain aspects of the laws on the use of languages in education in Belgium" v. Belgium, Judgment of 23rd July 1968, Series A 1968, párr. 34.

8 BOBBIO, N., Igualdad y libertad, Barcelona, Paidós, p. 54.

9 Resultando Segundo, Acción de Inconstitucionalidad 2/2010, resuelta el 16 de agosto de 2010

10 Corte IDH. Caso Masacre de las Dos Erres vs. Guatemala. Excepción Preliminar, Fondo, Reparaciones y Costas. Sentencia de 24 de noviembre de 2009. Serie C No. 211, Párrafo 200.

11 Corte IDH. Caso Artavia Murillo y otros (Fertilización in vitro) vs. Costa Rica. Excepciones Preliminares, Fondo, Reparaciones y Costas Sentencia de 28 noviembre de 2012 Serie C No. 257, Párrafo 272.

12 Sobre la tensión entre los principios democrático y de supremacía constitucional véase DE VEGA GARCÍA, P. (1983), "Constitución y democracia”, en LÓPEZ PINA, A. (Ed.), La Constitución de la Monarquía parlamentaria, Fondo de Cultura Económica, México, pp. 43-73.

13 REY CANTOR, E. (2008), Control de convencionalidad de las leyes y Derechos Humanos, Porrúa, México, p. 34; GARCÍA MORELOS, G. (2010), El control judicial difuso de convencionalidad de los Derechos Humanos por los tribunales ordinarios en México, Ubijus, México, p. 45.

14 CONTROL DE CONVENCIONALIDAD EX OFFICIO EN UN MODELO DE CONTROL DIFUSO DE CONSTITUCIONALIDAD. Registro: 160589. Tesis Aislada, Semanario Judicial de la Federación y su Gaceta, Libro III, diciembre de 2011, Tomo 1, Tesis: P. LXVII/2011(9a.), Página: 535.

15 Principios de Yogyakarta, Principios sobre la Aplicación de la Legislación Internacional de Derechos Humanos en Relación con la Orientación Sexual y la Identidad de Género.

16 Resultando Segundo, Acción de Inconstitucionalidad 2/2010, resuelta el 16 de agosto de 2010

17 Consejo Constitucional, Sentencia $n^{\circ}$ 2010-92, Question Prioritaire de Constitutionalité, Francia, de 28 de enero de 2011. 
18 Corte Europea de Derechos Humanos, Schalk and Kopf c. Austria, 24 de junio 2010, p. 23

19 Agencia Estatal Boletín Especial del Estado, Tribunal Constitucional (2012), en Boletín Oficial del Estado, nº 286, publicado miércoles 28 de noviembre, p. 219.

20 Hämäläinen v. Finland (Julio 2014) y; Chapin et Charpentier c. France (junio 2016).

21 FERRAJOLI, L. (2006), "Sobre los Derechos Fundamentales", Revista Mexicana de Derecho Constitucional (Cuestiones Constitucionales), $\mathrm{n}^{\circ} 15$

22 Oficina Internacional del Trabajo, "Discriminación en el lugar de trabajo", en Resumen Analítico. Declaración relativa a los Principios y Derechos Fundamentales en el Trabajo, p. 3. CERDÁ MARTÍNEZ-PUJALTE, C. (2005), "Los principios constitucionales de igualdad de trato y de prohibición de la discriminación: un intento de delimitación", Cuadernos Constitucionales de la Cátedra Fadrique Furió Ceriol, nº 50-51.

MATRIMONIO ENTRE PERSONAS DEL MISMO SEXO. EL ARTÍCULO 143 DEL CÓDIGO CIVIL DEL ESTADO DE OAXACA CONTIENE UNA DOBLE DISCRIMINACIÓN, AL PRIVAR A LAS PAREJAS HOMOSEXUALES DE LOS BENEFICIOS MATERIALES Y EXPRESIVOS QUE SE OBTIENEN CON DICHA INSTITUCIÓN. Tesis: 1a. CIII/2013 (TA); 10ª́poca, $1^{\text {a }}$ Sala, S.J.F. y su Gaceta, p. 962. Considerando Segundo. Acción de Inconstitucionalidad 2/2012, cit. 152/2013 MATRIMONIO. LA LEY QUE, POR UN LADO, CONSIDERA QUE LA FINALIDAD DE AQUEL ES LA PROCREACION Y/O LO DEFINE COMO EL QUE SE CELEBRA ENTRE UN HOMBRE UNA MUJER, ES INCONSTITUCIONAL. MATRIMONIO ENTRE PERSONAS DEL MISMO SEXO, NO EXISTE RAZON DE INDOLE CONSTITUCIONAL PARA NO RECONOCERLO. Tesis: 1a. CCLX/2014 (TA), $10^{\mathrm{a}}$ Época, $1{ }^{\text {a }}$ Sala.

MATRIMONIO. LA LEY QUE, POR UN LADO, CONSIDERA QUE LA FINALIDAD DE AQUÉL ES LA PROCREACIÓN Y/O QUE LO DEFINE COMO EL QUE SE CELEBRA ENTRE UN HOMBRE Y UNA MUJER, ES INCONSTITUCIONAL. Tesis: 1a. CIII/2013

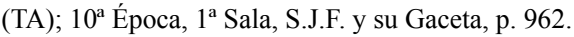

29 Considerando Noveno, Amparo Directo en Revisión 259/2013, resuelto el 30 de octubre del 2013.

30 CIDH, Caso Atala Riffo y niñas vs. Chile, Sentencia de 24 de febrero de 2013, párr. 83.

31 IGUALDAD. CUANDO UNA LEY CONTENGA UNA DISTINCIÓN BASADA EN UNA CATEGORÍA SOSPECHOSA, EL JUZGADOR DEBE REALIZAR UN ESCRUTINIO ESTRICTO A LA LUZ DE AQUEL PRINCIPIO. Registro 2003284. Tesis 1a. XCIX/2013 (10a.). Primera Sala. Décima Época. Semanario Judicial de la Federación y su Gaceta. Libro XIX, abril de 2013, Pág. 961

32 Ibidem, párr. 83-93.

33 MATRIMONIO. EL ARTÍCULO 143, PÁRRAFO PRIMERO, DEL CÓDIGO CIVIL PARA EL ESTADO DE OAXACA, EN LA PORCIÓN NORMATIVA QUE PRESCRIBE "PERPETUAR LA ESPECIE", COMO UNA DE LAS FINALIDADES DE ESA INSTITUCIÓN, ES CONTRARIO A LOS ARTÍCULOS 10. Y 4o. DE LA CONSTITUCIÓN POLÍTICA DE LOS ESTADOS UNIDOS MEXICANOS. Tesis: 1a. CCXV/2014, Gaceta del Seminario Judicial de la Federación, Décima Época, t. I, mayo de 2014, p. 548; MATRIMONIO ENTRE PERSONAS DEL MISMO SEXO. EL ARTÍCULO 143 DEL CÓDIGO CIVIL PARA EL ESTADO DE OAXACA CONTIENE UNA EXCLUSIÓN IMPLÍCITA Y NO UNA OMISIÓN LEGISLATIVA. Tesis: 1a. CCXV/2014, Gaceta del Seminario Judicial de la Federación, Décima Época, t. I, mayo de 2014, p. 548; Tesis: 1a. CV/2013, Seminario Judicial de la Federación y si Gaceta, Décima Época, t. I, abril de 2013, p. 963.

34 Tesis: 1a. CCXV/2014, Gaceta del Seminario Judicial...op. cit., p.548.

35 DERECHO AL LIBRE DESARROLLO DE LA PERSONALIDAD. ASPECTOS QUE COMPRENDE. Tesis Aislada, P. LXVI/2009, Semanario de la Suprema Corte de Justicia y su Gaceta, Novena Época, t. XXX, diciembre de 2009, p. 7.

36 Tesis: 1a. CV/2013, Seminario Judicial... op. cit., p. 963

37 Ley General de Desarrollo Social, Diario Oficial de la Federación, México, 20 de enero de 2004 38 ZÚÑIGA ORTEGA, A. V. (2011), Concubinato y familia en México, Biblioteca Digital de Humanidades, Universidad Veracruzana, Veracruz, p. 14. 
EL MATRIMONIO HOMOSEXUAL A LA LUZ DE LOS SISTEMAS INTERAMERICANO Y EUROPEO DE DERECHOS... Rogelio LÓPEZ SÁNCHEZ

22

HUNTER, N. D. (2012), The future impact of same sex marriage: More questions than answers, Georgetown University Law Center, Washington, D.C., nº 12-146.

40 DEVI, S. (1977), The World of Homosexuals, Bell Books editions, New Delhi, p. 51.

41 FRAGER, R. y FADIMAN, J. (2000), Abraham Maslow y la psicología transpersonal, Oxford University Press, $2^{\mathrm{a}}$ Edición, p. 462.

42 ROMAÑACH CABRERO, J. (2009), Bioética al otro lado del espejo (La visión de las personas con diversidad funcional y el respeto a los derechos humanos), Venezuela.

43 MATRIMONIO. LA LEY QUE, POR UN LADO, CONSIDERA QUE LA FINALIDAD DE AQUÉL ES LA PROCREACIÓN Y/O QUE LO DEFINE COMO EL QUE SE CELEBRA ENTRE UN HOMBRE Y UNA MUJER, ES INCONSTITUCIONAL. Tesis: 1a. CIII/2013

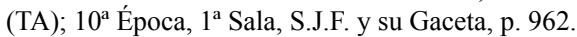

44 Considerando Segundo. Acción de Inconstitucionalidad 2/2012, resuelta el 16 de agosto del 2012.

45 Tesis: 1a. CV/2013, Seminario Judicial de la Federación y si Gaceta, Décima Época, t. I, abril de 2013 , p. 963.

46 ZÚNIIGA ORTEGA, (2011), p. 83.

47 Tesis: 1a. CV/2013, Seminario Judicial... op. cit. p. 963.

48 Esto se corresponde con la doctrina de la SCJN, presente en la siguiente tesis: MATRIMONIO. LA LEY QUE, POR UN LADO, CONSIDERA QUE LA FINALIDAD DE AQUÉL ES LA PROCREACIÓN Y/O QUE LO DEFINE COMO EL QUE SE CELEBRA ENTRE UN

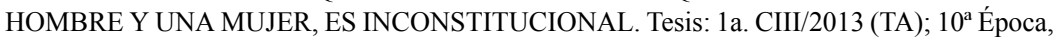
$1^{\text {a }}$ Sala, S.J.F. y su Gaceta, p. 962.

49 LIBERTAD CONFIGURATIVA DEL LEGISLADOR. ESTÁ LIMITADA POR LOS DERECHOS FUNDAMENTALES A LA IGUALDAD Y NO DISCRIMINACIÓN QUE OPERAN DE MANERA TRANSVERSAL. Tesis: 1a. CCLVIII/2014 (TA), $10^{\text {a }}$ Época, 1 a Sala. 50 HUNTER, (2012).

51 Oficina del Alto Comisionado de las Naciones Unidas para los Derechos Humanos en México (2003). Diagnóstico sobre la situación de los Derechos Humanos en México, Mundi-Prensa, México, D.F., p. 182.

52 Considerando Cuarto, Amparo en Revisión 581/2012, resuelto el 5 de diciembre de 2012.

53 Oficina del Alto Comisionado de las Naciones Unidas para los Derechos Humanos en México (2003). Diagnóstico sobre la situación de los Derechos Humanos en México, Mundi-Prensa, México, D.F., p. 183.

54 Sobre ello hay que recordar que Habermas advertiría que "la respuesta es que la institucionalización jurídica del procedimiento de creación democrática del derecho exige que se garanticen a la vez tanto los derechos fundamentales de tipo liberal, como los derechos fundamentales de tipo político- ciudadano. HABERMAS, J. (1998), Facticidad y validez, Madrid, traducción M. Jiménez Redondo.

55 MATRIMONIO ENTRE PERSONAS DEL MISMO SEXO, NO EXISTE RAZON DE INDOLE CONSTITUCIONAL PARA NO RECONOCERLO. Tesis: 1a. CCLX/2014 (TA), $10^{\mathrm{a}}$ Época, $1^{\text {a }}$ Sala

56 IGUALDAD. CASOS EN LOS QUE EL JUEZ CONSTITUCIONAL DEBE HACER UN ESCRUTINIO ESTRICTO DE LAS CLASIFICACIONES LEGISLATIVAS (INTERPRETACIÓN DEL ARTÍCULO 10. DE LA CONSTITUCIÓN POLÍTICA DE LOS ESTADOS UNIDOS MEXICANOS). Tesis aislada CXXXIII/2004, Primera Sala Novena Época, Semanario Judicial de la Federación y su Gaceta XX, diciembre de 2004, p. 361

57 VASCONCELOS MÉNDEZ, R. (2010), Una Corte para la Constitución (Justicia Constitucional y democracia en México), UNAM-IIJ, p. 16.

58 LAX, J. R. y PHILliPS, J. H. (2008), "Gay Rights in the States: Public and Policy Responsiveness", American Political Science Review, v. 103 n 3, agosto, p. 368.

59 SALAZAR UGARTE, P., AGUILÓ REGLA, J., et. al. (2009), Garantismo espurio, Fundación Coloquio Jurídico Europeo, Madrid.

60 BÉRUBÉ, A. (2011), "My Desire of History", en Essays in Gay, Community and Labor History, The University of North Carolina Press, Chapel Hill, p. 4; PALACIOS, R. (2011), La Conspiración del Movimiento Gay, Mandala Ediciones, Madrid, p. 11. 
61 VA: American Psychiatric Association (1973), Homosexuality and sexual orientation disturbance proposed change in DSM-II, Sexta impresión. Retiro de declaración de posición, Arlington, p. 44.

62 FUKUYAMA, F. (2019), Identidad. La demanda de dignidad y las políticas de resentimiento, Ariel, p. 52.

63 Justamente la aparición de esta noción en la jurisprudencia alemana se da con la Sentencia Solange de 1974, durante el estudio del artículo 24 de la Ley Fundamental relativo a la transferencia de poderes soberanos a instituciones interestatales, en la que advertía que aquella no permite que su estructura fundamental que les confiere identidad sea modificada sin revisión constitucional y en particular por la legislación de la institución. BON, P. (2014), "La identidad nacional o constitucional, una nueva noción jurídica", Revista Española de Derecho Constitucional, $\mathrm{n}^{\mathrm{o}} 100$, p. 171.

64 ROMBOLI, S. (2017), "Los contra-limites en serio y el caso Taricco: el largo recorrido de la teoría hasta la respuesta contundente pero abierta al diálogo de la Corte Constitucional Italiana", Revista de Derecho Constitucional Europeo, $\mathrm{n}^{\circ} 28$.

65 BON BOGDANDY, A. (2005), "Identidad constitucional -exploración de un fenómeno ambiguo con ocasión de la política de identidad europea de lege lata y lege ferenda-", Revista Española de Derechos Constitucional, $\mathrm{n}^{\mathrm{0}} 75$, p. 14. 